nia, and intravascular device infections in selected patient populations; medication side effects and complications; timing of antibiotic surgical prophylaxis; and appropriate use of antibiotic susceptibilities. These and the other potential hospital-wide clinical indicators will be evaluated at a number of hospitals that have already been selected as pilot test sites.

Incidentally, the new name Joint Commission on Accreditation of Healthcare Organizations replaces the name Joint Commission on Accreditation of Hospitals, reflecting the organization's broadening scope of interests.

\section{Review of Severity of Illness Working Group Meetings}

The members of the working group are Peter Gross, MD; B. Eugene Beyt, MD; Michael Decker, MD, MPH; Walter Hierholzer, Jr., MD; William Jarvis, MD; Richard Garibaldi, MD; Bryan Simmons, MD; Elaine Larson, PhD; William Scheckler, MD; and Lorraine Harkavy, RN (liaison from APIC).

The need for a severity of illness indicator to supplement the DRG (diagnosis related group) system is being reviewed. It is readily acknowledged that DRGs may be inaccurate in predicting costs for an individual case. However, does this problem persist when all patients in a hospital are considered together? If the problem does persist, can a DRG severity adjuster significantly improve accuracy!

We have begun to examine the major severity of illness indices. 'These are:
1. APACHE II (acute physiology and chronic health evaluation score, second generation)

2. CSI (computerized severity index)

3. Disease staging: clinical and coded versions

4. MEDISGROUPS (medical illness severity grouping system)

5. PMC (patient management categories)

After our first meeting, it became apparent that the various indices have been neither sufficiently studied individually nor compared with each other to permit us to make specific recommendations. However, we thought potential uses of these indices would include predicting risk of nosocomial infections and assessing utilization review, quality of care, appropriateness of care, and cost reimbursement.

Expansion of the role of the hospital epidemiologist was also discussed. The committee thought that we should expand our traditional role in infection control and infectious diseases to actively pursue involvement in quality assurance (QA) programs; we should apply our epidemiologic training and experience to the evaluation of data collected in QA studies.

The group considered undertaking a multicenter study to compare the value of the severity indices for the potential uses discussed above. After further discussion, it became clear that such studies were already underway at several institutions. We thought it would be more appropriate to try to set up a liaison with the Joint Commission on Accreditation of Healthcare Organizations. They have developed several clinical indicators for screening for the quality, appropriateness, and outcome of the care of patients in hospitals.
Dr. Gross, as a member of the Joint Commission's Hospital-wide Clinical Indicators Task Force, spoke with the Joint Commission's project managers for severity adjustment and for the clinical indicators. It was agreed to have SHEA's Severity of IIIness Index Working Group members meet with representatives of the Joint Commission. At that December 198' 7 meeting the plans of the loint Commission were presented to the SHEA working group. We discussed the proposed clinical indicators and the need for severity adjustment. Some indicators will require severity adjustment while others may not. The meeting was fruitful. Representatives of the Joint Commission have subsequently requested that our working group meet with them again to help with the evolution of' their data dictionary and plans for data analysis. These tasks will be the major focus of our committee in 1988.

The working group's interest in severity indices naturally led to the proposal to expand the role of the hospital epidemiologist to all QA activities and to work with the Joint Commission in evolving the proposed clinical indicators. These are exciting proposals that we hope will develop into concrete programs over the next two years.

Brief items of interest for the SHEA Newsletter may be sent to Roberl A. Weinstein, MD, SHEA Neusletter Editor, Division of Infectious Dis'ases, Michael Reese Hospital, Lake Shore Drive at 31.st St., Chicago, IL 60616. Copy must be typed, double-spaced, and may not exced fize pages. 


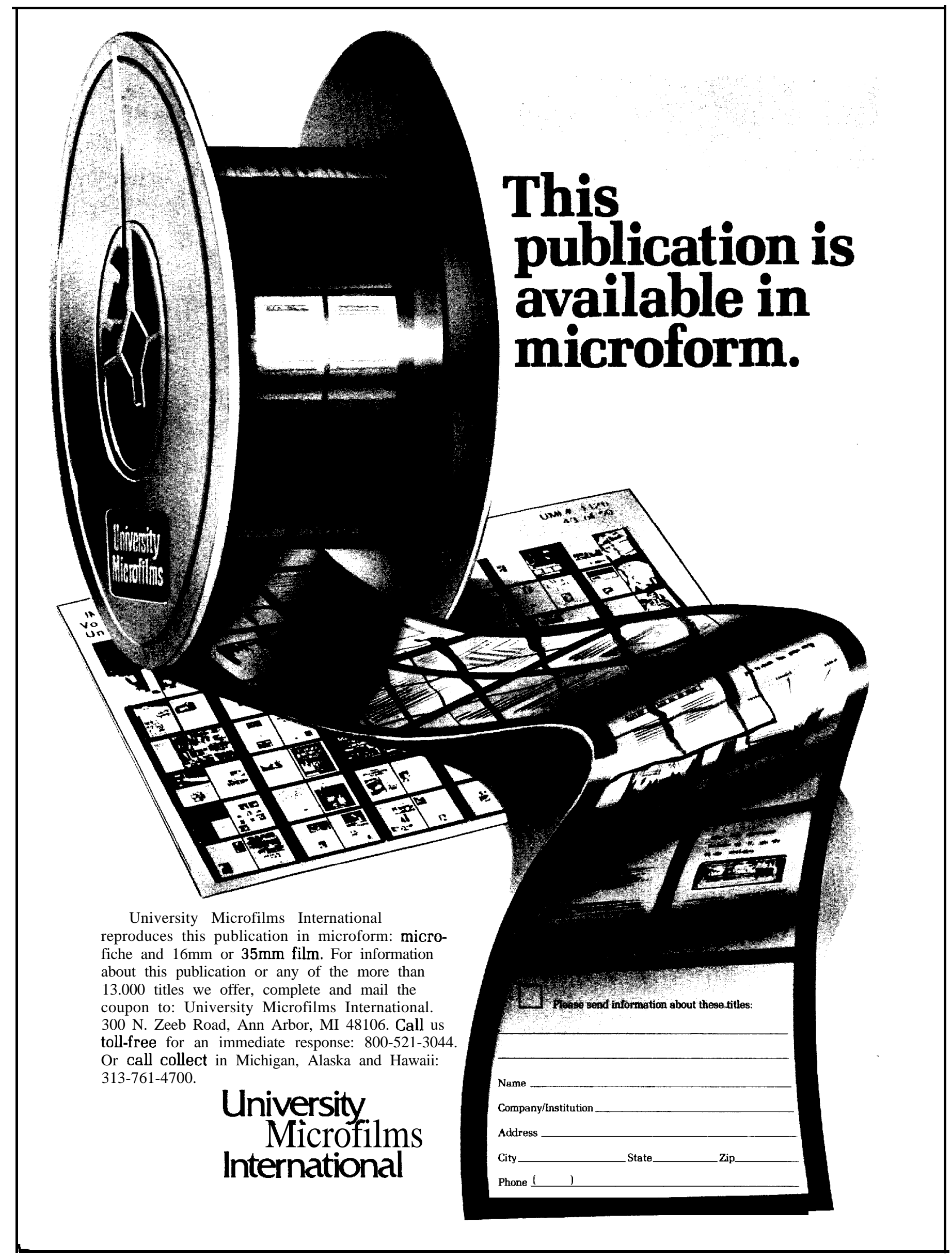

